\title{
Análise da aplicabilidade do modelo gerencial na administração municipal
}

\author{
Priscila Gomes de Araújo \\ Universidade Federal de Lavras \\ José Roberto Pereira \\ Universidade Federal de Lavras
}

Esse artigo tem como objetivo identificar e analisar as razões pelas quais a administração de um município do estado de Minas Gerais não adotou, integralmente, o modelo gerencial, tendo percorrido mais de 15 anos desde a última reforma do estado e mais de oito anos do Choque de Gestão de Minas Gerais. Para tanto, utilizou-se como parâmetro de análise e investigação o Índice de Administração Pública Gerencial (IAPG), desenvolvido por Freitas Jr. (2009), com base nos pressupostos teóricos do modelo de administração pública gerencial. Nesse sentido, foi realizada uma análise das características e objetivos do modelo gerencial, bem como a demonstração dos esforços para utilização desse modelo na administração pública brasileira nos três níveis de governo. A abordagem metodológica utilizada é qualitativa e de natureza teórico-empírica, adotando-se como instrumento de coleta de informações um roteiro de entrevistas abertas com prefeitos, chefes de gabinete, vereadores e secretários das duas últimas gestões municipais, que correspondem aos mandatos de 2001 a 2004 e de 2005 a 2008. Os resultados alcançados mostram que o maior entrave para a adoção efetiva do modelo de administração pública gerencial no município é a falta de capacidade de gerenciamento e conhecimento dos próprios prefeitos em relação ao modelo. Nesse sentido, verificou-se a necessidade de formar e qualificar os gestores públicos municipais em administração pública para atuarem, profissionalmente, na realidade local, bem como fortalecer os canais de participação da população, como forma de controle social da gestão pública.

Palavras-chave: gerencialismo; reforma administrativa do Estado; administração pública municipal; administração por resultados; municípios.

Análisis de la aplicabilidad del modelo de la gestión en la administración municipal Este artículo tiene como objetivo identificar y analizar las razones por las cuales la administración de un municipio en el estado de Minas Gerais, Brasil, no se ha adoptado en su totalidad, el modelo

Artigo recebido em 25 maio 2011 e aceito em 23 maio 2012. Este artigo é resultado de uma pesquisa financiada pelo CNPq (401649/2008-3) intitulada "Administração pública em municípios de pequeno porte do sul de Minas Gerais". 
de gestión, después de más de 15 años desde la última reforma del Estado y más de ocho años del Choque de Gestión de Minas Gerais. Para el análisis, se utilizó como parámetro el Índice de Gestión de la Administración Pública (GPI), desarrollado por Freitas Jr. (2009), basada en supuestos teóricos del modelo de gestión pública. En consecuencia, se realizó un análisis de las características y objetivos del modelo de gestión, así como la demostración de los esfuerzos para utilizar este modelo en la administración pública brasileña en los tres niveles de gobierno. El enfoque metodológico es cualitativo, teórico y empírico, adoptando como una herramienta para la recopilación de información de un guión de entrevistas con alcaldes, jefes de personal, concejales y secretarios de las dos últimas administraciones municipales, que corresponden a los mandatos de 2001 a 2004 y 2005 a 2008. Los resultados muestran que el mayor obstáculo para la adopción efectiva del modelo de gestión pública en el municipio es la falta de capacidad de gestión y el conocimiento de sus propios alcaldes del modelo. En este sentido, existe la necesidad de formar y calificar el gobierno municipal para actuar profesionalmente, en el local, así como fortalecer los canales de participación popular como un medio de control social de la administración pública.

Palabras clave: gerencialismo; reforma administrativa del estado; administración pública municipal; gestión por resultados; municipalidad.

\section{Applicability analysis of the model management in municipal administration}

This objective of this article is to identify and analyze the reasons why the administration of a municipality in the state of Minas Gerais, Brazil, has not adopted in full, the management model, given the elapsed time over 15 years since the last reform of the state and more than eight years of "management shock" of Minas Gerais. For this purpose, we used as a parameter to analyse and research the Index of Public Administration Management (IAPG), developed by Freitas Jr. (2009), based on theoretical assumptions of the model of public management. Accordingly, we performed an analysis of the characteristics and objectives of the management model, as well as the demonstration of efforts to use this model in Brazilian public administration at all three levels of government. The methodological approach is qualitative, theoretical and empirical, adopting as a tool for gathering information a script interviews with mayors, chiefs of staff, councilors and secretaries of the last two municipal administrations, which correspond to the mandates of the 2001 to 2004 and 2005 to 2008. The results show that the biggest obstacle to the effective adoption of the model of public management in the municipality is the lack of management capacity and knowledge of their own mayors from the model. In this sense, there is a need to train and qualify in the municipal government to act professionally in the local as well as strength the channels of popular participation as a means of social control of public administration.

KEY WORDs: managerialism; administrative reform of the State; municipal public administration; management by results; municipalities.

\section{Introdução}

No contexto complexo das relações entre Estado, sociedade e mercado no Brasil, observa-se, historicamente, o protagonismo do Estado em relação aos outros setores, o que colaborou para que a trajetória das reformas administrativas fosse marcada pela centralização do Estado. Além disso, desde o período colonial até o século XX, a administração pública no Brasil 
foi caracterizada pelo forte traço do patrimonialismo. Assim, no sentido de superar a forma patrimonialista de governar, várias reformas administrativas foram empreendidas desde o governo de Getúlio Vargas.

Foi Getúlio Vargas que promoveu a primeira reforma administrativa no Brasil, conhecida como Reforma Burocrática, ao buscar introduzir a burocracia no serviço público. Para isso, criou o Departamento de Administração do Serviço Público (Dasp), órgão que assumiu a responsabilidade de promover a estruturação básica do aparelho administrativo, instituir o concurso público, as regras para admissão e treinamentos dos servidores públicos. A partir de então sucede uma sequência de reformas administrativas do Estado caracterizadas pela incompletude de seus propósitos. Por isso, não só no Brasil, mas em países do mundo todo, "as políticas de reformas são conhecidas como políticas que têm baixa performance e alta persistência, portanto, são políticas que falham sequencialmente" (Rezende, 2002:125).

A produção acadêmica que discute as razões de incompletude das reformas do Estado é bastante "diversa, apresentando mecanismos causais bastante heterogêneos" (Rezende, 2002:125). Rezende (2002) relaciona os diversos estudos que tratam dessa questão, destacando-se os seguintes: Hyneman (1939), estudo mais longínquo sobre o tema; Herbert Kaufman (1956), que aponta que as reformas administrativas são políticas incompletas, pois trazem princípios estruturadores incompatíveis; March e Olson (1983), que analisam, à luz da experiência histórica, as reformas nos Estados Unidos no século passado; Paul Light (1997), que ilustra o quanto novas reformas são produzidas para tratar de problemas crônicos no aparato burocrático.

A última reforma administrativa do Estado ficou conhecida como "administração pública gerencial" e surgiu na segunda metade do século XX, motivada pela busca de meios capazes de enfrentar o desequilíbrio fiscal dos Estados devido às funções econômicas e por problemas com as mudanças tecnológicas, financeiras e comerciais que emergiam com a globalização (Abrucio, 2005). Além disso, como observa Misoczky (2004), essa reforma gerencial teve como foco o alcance de resultados a partir de metas preestabelecidas, considerando o cidadão como consumidor dos serviços públicos. São práticas introduzidas na administração pública que focam a descentralização de processos e a delegação de poder, práticas essas advindas do modelo de gestão das organizações privadas (Kettl, 2005).

No Brasil, a reforma gerencial foi iniciada em 1995, no governo de Fernando Henrique Cardoso, e foi difundida em estados da federação por meio de programas como o Choque de Gestão em Minas Gerais (Bresser-Pereira, 2005). No entanto, como observa Torres (2004:141), verifica-se a incompletude dessa reforma com a forte presença do "patrimonialismo na cultura política da administração pública [com] que o Brasil convive até os dias de hoje".

Considerando esse contexto de reformas e o Choque de Gestão em Minas Gerais, Freitas Jr. (2009) realizou um estudo com 177 municípios do sul de Minas Gerais a respeito da adoção do modelo gerencial de administração pública, demonstrando mais uma evidência da incompletude dessa reforma ao constatar que nenhum dos municípios estudados adotou o referido modelo. Diante desse contexto, de mais de 15 anos para a efetivação do modelo gerencial de administração pública nos três níveis de governo e, especificamente, do Esta- 
do de Minas Gerais em difundir esse modelo no âmbito municipal por meio do programa Choque de Gestão, emerge a questão que fundamenta o presente artigo: quais as razões que dificultam ou impedem a adoção efetiva do modelo gerencial na administração pública municipal? Dessa forma, o objetivo central deste artigo é mostrar as razões pelas quais a administração pública de um município do sul do estado de Minas Gerais não adotou, integralmente, o modelo de administração pública gerencial, tendo em vista o contexto político em que se insere.

\section{Administração pública gerencial}

Paes de Paula (2005) aponta duas correntes de pensamento que orientaram a constituição do modelo da nova administração pública: o pensamento neoliberal e a teoria da escolha pública. Para essa autora, o pensamento neoliberal e a teoria da escolha pública serviram de base para o início e a expansão do movimento da nova administração pública.

As ideias do pensamento liberal e neoliberal que deram sustentação ao gerencialismo estão relacionadas à "amplitude ideal do papel do Estado na sociedade e na economia" (Paes de Paula, 2005:28), o qual teria as seguintes funções: manter a segurança interna e externa, garantir o cumprimento dos contratos e prestar serviços essenciais de utilidade pública. Para essa autora, esse movimento defende o laissez-faire, ou não intervenção do Estado no mercado. Segundo Paes de Paula (2005), o pensamento neoliberal não previa crises do mercado. No entanto, com o aparecimento das várias crises econômicas que culminaram com a quebra da bolsa de Nova York em 1929, colocaram-se em questão as premissas não intervencionistas do pensamento liberal.

Diante de tal cenário, um dos mais importantes economistas do século XX, Jonhn Maynard Keynes, fez uma reavaliação sobre o pensamento liberal e elaborou sua tese de pleno emprego, atribuindo ao Estado a função de intervir na economia e estimular o crescimento econômico para garantir o bem-estar social. O sucesso dessas medidas no pós-guerra, de 1940 a início de 1970, consolidou a crença de que as crises capitalistas são contornáveis quando o governo utiliza-se do seu poder de tributar, empregar e investir (Paes de Paula, 2005).

Com outra visão, os teóricos da escolha pública, diferentemente dos neoliberais, que reforçavam suas visões sobre a eficiência do mercado em relação ao Estado, elaboravam análises que sustentariam a crítica da burocracia pública e do papel do Estado. A teoria da escolha pública defende que os princípios econômicos devem ser aplicados para explicar temas políticos como: a teoria do Estado, as regras eleitorais, o comportamento dos eleitores, os partidos políticos e a burocracia. É uma teoria que também partilha do postulado comportamental básico da economia neoclássica: o utilitarismo nas interações econômicas, sociais e políticas. Para Paes de Paula (2005) essa proposta oferece uma justificativa racional para a privatização dos serviços públicos e se junta com a argumentação neoliberal de que o provimento desses pelo mercado é mais eficiente e satisfatório. Esses teóricos tratam também da questão da transferência de serviços públicos para a iniciativa privada, abordando que tal fato geraria a 
vantagem de estimular a ação racional maximizadora e estimularia a ação reguladora, fiscalizadora e controladora do Estado, de modo a garantir a transparência e a distribuição das informações (Paes de Paula, 2005).

Pode-se considerar que tanto o pensamento neoliberal como a teoria da escolha pública almejavam um modelo de administração pública inovador quanto à forma de conduzir e administrar os assuntos públicos de governo. Assim, surgem as recomendações de aproximar o modelo de gestão das organizações públicas às práticas gerenciais utilizadas no setor privado, como a introdução de conceitos de avaliação de desempenho, eficiência e responsabilidade (Hood, 1995). Inicia-se então um novo modelo de administração pública que se torna uma "nova ortodoxia" (Pollit, 2000).

Por outro lado, a chamada Nova Administração Pública (Paes de Paula, 2005) foi também embasada nas ideias de Antony Giddens, assessor do então primeiro-ministro do Reino Unido Tony Blair. A proposta de Giddens (1999) era a de fazer uma política mais integrada, que abrangia cada um dos principais setores da sociedade, no sentido de ampliar a democracia. Giddens (1999) fundamenta suas ideias apoiado na integração entre o setor público e privado ao justificar a dinâmica do mercado com o propósito de um bem-estar social (Paes de Paula, 2005).

Com a decadência do neoliberalismo e da social-democracia de velho estilo, Giddens (1999:36) lança a proposta de uma Terceira Via, "que se refere a uma estrutura de pensamento e de prática política que visa a adaptar a social-democracia a um mundo que se transformou fundamentalmente ao longo das duas ou três últimas décadas”. Enquanto a social-democracia considerava importante a segurança econômica e o neoliberalismo buscava competitividade na geração de riqueza, a Terceira Via ocupa-se em aliar o dinamismo do mercado com a questão do interesse público (Giddens, 1999). Ainda, segundo esse autor, enquanto os neoliberais defendem um Estado mínimo e os sociais-democratas desejam expandir o poder do Estado, a política da Terceira Via se propõe a reconstruí-lo.

$\mathrm{Na}$ “Terceira Via”, proposta por Giddens (1999), a reforma do Estado deve ser baseada na integração e participação dos principais setores da sociedade, caracterizando o que esse autor chamou de nação cosmopolita. É proposta a reconstrução dos preceitos do welfare state e não seu desmantelamento, ou seja, o welfare positivo: investimento no capital humano, com benefícios tanto econômicos quanto psicológicos, com desenvolvimento ativo da sociedade civil; igualdade como inclusão e desigualdade como exclusão; e a inclusão pelo "liberalismo cívico", que cultiva a nação cosmopolita e melhora a educação pública, a saúde e os níveis de criminalidade.

Paes de Paula (2005) contesta a "Terceira Via" proposta por Giddens afirmando que, apesar desse modelo propor uma posição oposta às visões neoconservadoras, na prática o modelo faz de suas premissas econômicas e morais uma continuidade do modelo neoliberal. Paes de Paula (2005) afirma que esse modelo se baseia exclusivamente em uma eficiência técnica, dando pouca importância à evolução de uma maneira de gerir o Estado por meio do comprometimento com a dimensão sociopolítica e democrática. Nos Estados Unidos, à época do governo Bill Clinton, o movimento "Reinventando o Governo" se desenvolveu simultaneamente ao desenvolvimento da "Terceira Via" que ocorreu na Inglaterra. 
Para Osborne e Gaebler (1995), o problema das organizações governamentais está centrado no sistema de gestão. Eles defendem que as pessoas não são o problema maior para as novas demandas de eficiência e eficácia desse tipo de organização, e que somente por meio de reformas das instituições e dos incentivos a burocracia se tornará apta a responder a essas novas demandas.

A reinvenção do governo, nas ideias de Osborne e Gaebler (1995), está baseada em um conjunto de 10 princípios estabelecidos pelos autores, que são: governo catalizador — navegando em vez de remar; o governo pertence à comunidade - dando responsabilidade ao cidadão, em vez de servi-lo; governo competitivo — introduzindo a competição na prestação de serviços; governo orientado por missões - transformando órgãos burocratizados; governo de resultados — financiando resultados, não recursos; governo e seus clientes — atendendo às necessidades do cliente e não à burocracia; governo empreendedor — gerando receitas em vez de despesas; governo preventivo - a prevenção em lugar da cura; governo descentralizado — da hierarquia à participação e ao trabalho de equipe; governo orientado para o mercado — induzindo mudanças por meio do mercado.

Para Hood (1995), a administração pública gerencial possui as seguintes orientações: desagregação do serviço público em unidades especializadas e centros de custos; competição entre organizações públicas e entre organizações públicas e privadas; uso de práticas de gestão provenientes da administração privada; atenção à disciplina e parcimônia; administradores empreendedores com autonomia para decidir; avaliação de desempenho; avaliação centrada nos outputs.

Há também as críticas quanto ao novo modelo da administração pública que adota práticas gerenciais. Para Paes de Paula (2005:81), o novo modelo de administração pública possui "caráter centralizador" e também não consegue tratar ainda algumas dinâmicas da política, pois o gerencialismo "não se volta para questões que envolvem a complexidade da gestão, como, por exemplo, a integração entre os aspectos técnicos e políticos".

Paes de Paula (2005) aponta ainda os limites que esse modelo reproduz, como: a centralização do poder e a criação de elites burocráticas; complexidade dos sistemas administrativos e do aspecto sociopolítico de gestão pública; dificuldade de adaptar técnicas do setor privado ao setor público; e incompatibilidade existente entre a lógica gerencial e o interesse público. De maneira geral, Paes de Paula (2005) critica esse modelo quanto à questão do mesmo não tratar da dimensão sociopolítica, apesar de seu discurso participativo. Para a autora, o modelo gerencial na administração pública dificulta o comprometimento com a participação cidadã e a ampliação da democratização do Estado.

\section{O movimento gerencial no Brasil}

Diante de uma crise fiscal enfrentada pelo Estado, a proposta do modelo gerencial chegou à administração pública brasileira por meio da reforma administrativa de 1995 como uma alternativa para combater a crise fiscal e a exaustão financeira por meio da redução de gastos, ajuste fiscal e privatizações. Essa reforma propunha, também, superar a insatisfação advinda 
do modelo burocrático, que até então oferecia baixa qualidade na prestação de serviços públicos prestados aos cidadãos (Fadul e Silva, 2008). Essa reforma se baseava em um conjunto de políticas reformistas que deveria atingir tanto a estrutura administrativa pública, enfatizando a adoção de práticas gerenciais, como setores da produção de bens para o mercado, com privatizações de empresas e serviços públicos (Fadul e Silva, 2008).

Empenhado, efetivamente, em mudar o modelo de administração pública brasileira, o então presidente Fernando Henrique Cardoso criou o Ministério da Administração e Reforma do Estado (Mare), para tratar de assuntos especificamente referentes a essa reforma. Para o então presidente da república, a administração pública gerencial é "baseada em conceitos atuais de administração e eficiência, voltada para o controle dos resultados e descentralizada para poder chegar ao cidadão, que, numa sociedade democrática, é quem dá legitimidade às instituições e que, portanto, se torna 'cliente privilegiado' dos serviços prestados pelo Estado" (Brasil, 1995:1).

A proposta da reforma no Brasil foi fundamentada em três dimensões: 1) institucionallegal, que trata da reforma do sistema normativo e legal da administração pública; 2) cultural, visando à transição de uma cultura burocrática para uma cultura gerencial; 3) gestão pública, que põe em prática o aperfeiçoamento da administração pública burocrática em paralelo com a introdução da administração pública gerencial, tendo em vista a modernização da estrutura organizacional e dos métodos de gestão (Brasil, 1995).

Segundo Bresser-Pereira (2005), a reforma objetivava: a) a busca da eliminação da crise fiscal, através de controle rigoroso das despesas públicas e do aumento das receitas públicas; b) a transformação da administração pública burocrática em gerencial, com foco nos resultados em detrimento do controle dos processos; c) a melhoria do atendimento das demandas sociais, mediante a criação de instituições mais descentralizadas e mais próximas dos cidadãos. Segundo Fadul e Silva (2008), a reforma do Estado brasileiro propunha combater o problema de crise fiscal por meio da redução de gastos, ajustes fiscais e privatizações. Esses autores consideram que a nova administração pública no Brasil conseguiu alguns êxitos no campo instrumental, objetivo, mas no campo substantivo, social, não conseguiu dar conta de muitas questões. Portanto, consideram que é preciso superar barreiras políticas, ideológicas e corporativas existentes no âmbito do funcionalismo público e nos atuais desenhos organizacionais e institucionais para o gerencialismo se estabelecer nas organizações públicas brasileiras (Fadul e Silva, 2008).

Seguindo a mesma linha de raciocínio, Paes de Paula (2005) concluiu que o modelo de gestão pública gerencial no Brasil por meio da reforma de 1995 não resultou em uma ruptura com a linha tecnocrática, além de continuar reproduzindo o autoritarismo e o patrimonialismo. Para essa autora, o processo decisório continuou como um monopólio do núcleo estratégico do Estado e das instâncias executivas, sendo o ideal tecnocrático reconstituído pela nova política de recursos humanos. Por outro lado, a despeito do discurso participativo da nova administração pública, essa autora considera que a estrutura e a dinâmica do Estado pós-reforma não garantiram uma inserção da sociedade civil nas decisões estratégicas e na formulação de políticas públicas. Para a autora, "a reforma perdeu seu ímpeto no que se refere ao redesenho institucional e acabou tornando o ajuste fiscal o elemento preponderante" (Paes de Paula, 2005:136). 
A partir da reforma do Estado vários estados da federação começaram, também, a se articular na busca de construir suas próprias reformas com base no modelo proposto pelo governo federal. Como exemplo têm-se os estados da Bahia, Ceará, Pernambuco, São Paulo, Acre e Minas Gerais (Cunha Junior, 2004:2).

No caso de Minas Gerais, o estado buscou reformar sua gestão administrativa "copilando inclusive as razões de sucesso e fracasso, para que fossem potencializadas ou evitadas, adaptando-as à necessidade, à realidade e à cultura local” (Cunha Junior, 2004:2).

A iniciativa de elaborar um modelo de gestão revigorador em Minas Gerais partiu do governador Aécio Neves em 2002, em sua campanha eleitoral. Naquela época, o estado enfrentava uma crítica situação financeira advinda de mais de uma década de défices fiscais crônicos. Para o governador, a solução para os problemas enfrentados pelo estado não se resumia somente em "ajustar-se à dura realidade fiscal caracterizada pelo déficit", mas fazer com que o estado "reencontrasse seu rumo dentro de si mesmo, do Brasil e do mundo" (Vilhena et al., 2006:11). Para isso, "era preciso aprender a fazer mais e melhor com menos para transformar, passo a passo, em realidade, o sonho de fazer de Minas Gerais o melhor Estado para se viver no Brasil" (Vilhena et al., 2006:11).

Elaborou-se, então, o "choque de gestão", ou seja, um modelo de gestão formulado por "um conjunto de medidas de rápido impacto, para modificar, de vez, o padrão de comportamento da Administração Estadual, imprimindo-lhe um ritmo consentâneo com a contemporaneidade própria de uma gestão eficiente, efetiva e eficaz" (Vilhena et al., 2006:15).

O "Choque de Gestão" trata de uma reorganização da gestão governamental por meio da incorporação de "diversas inovações e iniciativas de aperfeiçoamento da gestão pública" (Cunha Junior, 2004:1). É um processo de reforma que tem como modelo a gestão privada, no qual se faz uso das técnicas de planejamento e dos critérios permanentes de avaliação de resultados, tanto institucionais quanto pessoais, entre outros elementos. Nesse sentido, a estrutura administrativa do governo de Minas foi modernizada, buscando a racionalização na utilização de recursos públicos, estabelecendo-se prioridades e metas a serem cumpridas, entre outros aspectos (Vilhena et al., 2006). Uma das primeiras medidas tomadas para o funcionamento do "Choque de Gestão" foi a criação da Secretaria de Estado de Planejamento e Gestão (Seplag), que passou a se responsabilizar pela integração das políticas de planejamento e de gestão.

O "Choque de Gestão" foi dividido em duas etapas: 2003-06 e 2007-10. Segundo Vilhena e colaboradores (2006), na primeira etapa, a prioridade foi trabalhar com políticas de gestão pública que orientassem o ajuste fiscal ortodoxo por meio de repressão fiscal, gestão orçamentária, financeira e contábil, políticas de reajuste salariais e previdência do servidor. De acordo com esses autores, esperava-se que, por meio do ajuste fiscal, se obteria credibilidade e atração de investimento como precondição para o desenvolvimento. Porém, "o ajuste fiscal puro impôs uma agenda predominantemente negativa de cortes e restrições", acarretando graves efeitos colaterais sobre a capacidade de crescer (Vilhena et al., 2006:27). Para esses autores, a segunda etapa teve como propósitos trabalhar na orientação de uma nova administração, racionalizando e melhorando a gestão, e promover o desenvolvimento por meio da governança social, fortalecendo o Estado, o mercado e o terceiro setor para o alcance de resultados concertados (Vilhena et al., 2006). 
Para Vilhena e colaboradores (2006:31), "a reforma gerencial deixou várias lições: a necessidade de se construir um norte, um ideal de desenvolvimento, de se promover inovações gerenciais e de integrar as políticas de gestão, alinhando-as para trilhar o caminho escolhido". Essas lições serviram de base para que o choque de gestão fosse formulado de forma "eclética e inteligente, combinando elementos dos programas de ajustes com iniciativas vigorosas voltadas para o desenvolvimento do Estado" (Vilhena et al., 2006:32).

As considerações apresentadas a respeito do "Choque de Gestão" reforçam os argumentos de incompletude das reformas administrativas do Estado, em seus aspectos estruturadores. Além disso, deve-se considerar que a reforma administrativa no Brasil alcançou poucos estados da federação e alcançou, menos ainda, os municípios brasileiros.

Com objetivo de verificar entre as administrações de 177 municípios do sul de Minas Gerais aquelas que adotam o modelo gerencial, Freitas Jr. (2009) realizou uma pesquisa por meio de indicadores. Os indicadores utilizados em sua pesquisa fazem parte do Índice de Administração Pública Gerencial Municipal (IAPG-M) elaborado pelo autor. Para desenvolvê-lo, Freitas Jr. (2009) se apoiou nas duas dimensões mais relevantes da administração pública gerencial, referenciadas por Paes de Paula (2005): institucional-administrativa e econômico-financeira. Fundamentado em Paes de Paula (2005), o autor considerou que a dimensão sociopolítica não é levada em conta no modelo gerencial e, portanto, não deveria constar na composição do IAPG-M.

Freitas Jr. (2009) utilizou quatro classes como parâmetro para a classificação dos municípios. São elas: "A", municípios que conseguem colocar em prática acima de 75\% dos indicadores utilizados para caracterizar uma administração pública do tipo gerencial; "B", municípios que conseguem aplicar entre 50\% e 75\% dos indicadores gerenciais; "C" e "D", municípios que foram classificados como tendo outro tipo de administração pública que não a gerencial, pois aplicam menos de $50 \%$ dos indicadores gerenciais.

Segundo Freitas Jr. (2009), com base nos critérios adotados em sua pesquisa, não consta entre os 177 municípios do sul de Minas Gerais nenhum município que adota, integralmente, o modelo de administração pública gerencial, ou seja, nenhum desses municípios alcançou a classe "A". Na classe "B" foram identificados apenas 39 municípios, o que sinaliza uma posição intermediária desses municípios, ou mesmo uma tendência ao modelo gerencial. Essa situação intermediária pode expressar "um tipo de administração pública 'híbrida', com elementos gerenciais, patrimoniais, burocráticos e societais" (Freitas Jr, 2009:112). A classe "C" está representada por 86 municípios e a classe “D”, por 52.

Além disso, o estudo de Freitas Jr. (2009) revelou a inexistência de correlações entre gerencialismo e partido político. Isso porque, segundo o autor, a política brasileira é, tradicionalmente, mais voltada para a pessoa do candidato ou governante do que para uma ideologia partidária. Quanto à relação entre gerencialismo e porte do município, o estudo de Freitas Jr. (2009) constatou que o gerencialismo encontra-se mais difundido entre os municípios de médio e grande porte do que entre os municípios de pequeno porte.

Portanto, pode-se considerar que o modelo gerencial de administração pública se caracteriza, também, pela incompletude da reforma administrativa no âmbito municipal e não alcançou a maioria dos municípios estudados. Assim, este artigo mostrará como se comporta um dos municípios mineiros que se encontra na classe "B" do estudo de Freitas Jr. (2009) em relação à reforma administrativa do Estado no Brasil e ao "Choque de Gestão" em Minas Gerais. 


\section{Metodologia}

Este artigo se baseia nos resultados de uma pesquisa qualitativa de natureza teórico-empírica, cujo instrumento de coleta de informações adotado foi um roteiro de entrevistas abertas com prefeitos, chefes de gabinete, vereadores e secretários das duas últimas gestões municipais, que correspondem aos mandatos de 2001 a 2004 e de 2005 a 2008 . Foram entrevistadas 14 pessoas que durante as gestões pesquisadas ocuparam os seguintes cargos: prefeito (1), chefe de gabinete (1), vereadores (4) e secretários (8). A fim de resguardar a identificação dos entrevistados, optou-se por nomeá-los como Entrevista 1, Entrevista 2, sucessivamente até Entrevista 14. As questões foram elaboradas com base nos indicadores e variáveis que compõem o IAPG-M, como pode ser observado no quadro seguinte.

\section{Quadro}

\section{Estrutura de indicadores e variáveis que compõem o IAPG-M}

\begin{tabular}{|c|c|c|c|}
\hline IAPG-M & imensão & Indicadores & Variáveis \\
\hline \multirow{4}{*}{ 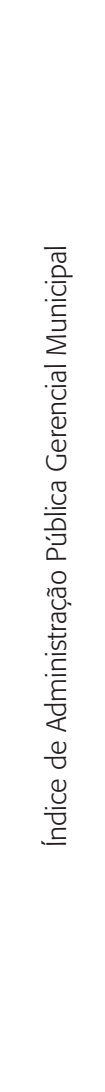 } & \multirow{3}{*}{ 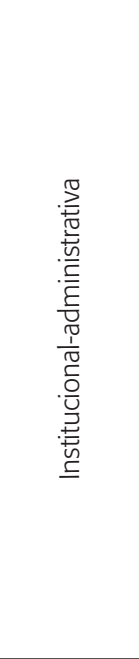 } & Recursos humanos & $\begin{array}{l}\text { Quantidade de funcionários para cada } 100 \text { habitantes } \\
\text { \% de funcionários com ensino superior } \\
\text { \% de funcionários com pós-graduação } \\
\text { Existência de administração indireta }\end{array}$ \\
\hline & & Instrumento de gestão & $\begin{array}{l}\text { Existência de código de obras } \\
\text { Existência de lei de parcelamento do solo } \\
\text { Existência de lei de zoneamento } \\
\text { Existência de plano diretor } \\
\text { Existência de cobranças de IPTU }\end{array}$ \\
\hline & & $\begin{array}{l}\text { Articulação interinstitucional e } \\
\text { participação do cidadão }\end{array}$ & $\begin{array}{l}\text { Quantidade de conselhos gestores existentes } \\
\text { Existência de consórcio público com outros entes federativos } \\
\text { Existência de convênios ou parceria com o setor privado } \\
\text { Existência de apoio do setor privado ou de comunidades na adminis- } \\
\text { tração municipal } \\
\text { Participação em comitê de bacia hidrográfica }\end{array}$ \\
\hline & 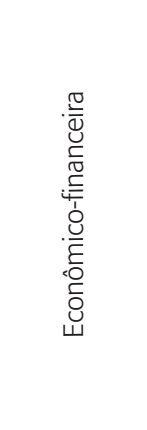 & $\begin{array}{l}\text { Responsabilidade fiscal e } \\
\text { aplicação dos recursos }\end{array}$ & $\begin{array}{l}\text { Aplicação de recursos em saúde - cumprimento do \% previsto em lei } \\
\text { Aplicação de recursos em educação - cumprimento do \% previsto } \\
\text { em lei } \\
\text { Despesas com pessoal - cumprimento do \% máximo previsto em lei } \\
\text { Cumprimento da Lei de Responsabilidade Fiscal } \\
\text { Cumprimento de limites legais para o endividamento do município } \\
\text { Indicador de desenvolvimento tributário e econômico } \\
\text { Participação da dívida na receita corrente líquida } \\
\text { Esforço orçamentário em educação - \% orçamento investido } \\
\text { Esforço orçamentário em saúde - \% orçamento investido }\end{array}$ \\
\hline
\end{tabular}

Fonte: Freitas Jr. (2009:89). 
Vale lembrar que esses indicadores e variáveis representam categorias da administração pública gerencial e as temáticas gerenciais elaboradas no estudo de Freitas Jr. (2009). O município estudado obteve o Índice de 0,59 (IAPG-M), é o nono colocado nesse índice entre os 177 municípios da região sul de Minas e está entre os 39 da classe "B" do estudo de Freitas Jr. (2009). Com população de 92.150 habitantes (IBGE, 2010), é um município polo da microrregião onde está inserido e estava alinhado com as políticas de modernização administrativa, "Choque de Gestão", do governo de Minas. Essas foram as razões metodológicas da escolha desse município para o estudo.

\section{0 modelo gerencial na administração pública municipal: principais entraves}

A apresentação dos resultados a seguir foi organizada de acordo com os quatro indicadores que compõem o IAPG-M, quais sejam: recursos humanos; instrumentos de gestão; articulação interinstitucional e participação do cidadão; responsabilidade fiscal e aplicação dos recursos.

$\mathrm{O}$ indicador recursos humanos tem como objetivo avaliar a eficiência dos servidores públicos na prestação de serviços. Em 2001, havia uma proporção de 2,3 funcionários para 100 habitantes, já em 2008 essa proporção passou para 2,96 funcionários por 100 habitantes. Essa variável mostra que o grau de eficiência na utilização de pessoal empregado na prefeitura sofreu uma queda significativa. Isso indica maiores gastos dos recursos públicos com folha de pagamento de pessoal, o que pode representar ineficiência na gestão de pessoal. Mostra, também, que não há competição na prestação de serviços que pudesse trazer mais eficiência, ou seja, não há concorrência interna e externa na prestação de serviços oferecidos pela prefeitura municipal. Como observa Osborne e Gaebler (1995), esses aspectos podem afetar a inovação, o orgulho e a motivação dos servidores públicos.

Para a maioria dos entrevistados o número de funcionários era suficiente nas gestões pesquisadas, e até mesmo mais que suficiente, para atender a demanda de serviços prestados à população. Eles afirmam que o número de funcionários poderia ser ainda mais reduzido, ao mesmo tempo prestando serviços com eficiência à população.

[...] o número era suficiente sim, poderia ser que não estava direcionado adequadamente, devia ter algum setor que estava meio inchado e outro setor com falta de demanda [...] (Entrevista 09).

Eu acho que esse número (de funcionário) excessivo de pessoas realmente poderia ser menor, agora como se trata de administração pública é, o poder público trabalha muito com o social porque se não for ali o local de trabalho daquela pessoa ela pode ter dificuldade de se manter também então há um paradoxo aí entre poder ter um número menor porque tecnologicamente isso é possível e ver o outro lado social também das pessoas, do grupo, da comunidade. Se deixar quinhentas pessoas sem trabalho na prefeitura, são quinhentos problemas que vamos ter também, desemprego que gera outro e desencadeiam outras coisas né [...], então eu acho que é todo um paradoxo que tem que ser resolvido (Entrevista 08). 
Nesse sentido, a prefeitura do município em questão não tem adotado o princípio gerencial denominado downsizing como estratégia de sua administração, como considera Rezende (2002:120): “As políticas de downsizing, ou redução do número de funcionários públicos, como estratégia de reforma da administração pública, têm sido um dos componentes das reformas gerenciais no mundo desenvolvido e em desenvolvimento".

O percentual de funcionários ativos com curso superior/pós-graduação é, relativamente, baixo, tendo em vista que do total de 2.699 servidores ativos, em 2008, apenas 34\% possuíam curso superior e apenas $6,6 \%$ possuíam pós-graduação, conforme dados do IBGE (2010). Essa situação denota falta de plano de formação e qualificação dos servidores públicos municipais, reforçando, com isso, a probabilidade de ineficiência na prestação de serviços. É relevante observar que há no município um grande número de cursos superiores oferecidos por universidades públicas e privadas, fato que poderia facilitar e estimular os funcionários a cursarem ensino superior. No entanto, isto não acontece. Porém, segundo os entrevistados, o grande entrave para a qualificação são a falta de incentivo e a cobrança de resultado por parte da administração municipal. Além disso, os entrevistados mencionaram que há desinteresse por parte dos servidores públicos devido à estabilidade no emprego, o que faz com que se acomodem e não se interessem em buscar possibilidades de crescimento profissional, pois não possuem a preocupação de serem julgados ou punidos.

Eu acho que existe [interesse dos funcionários em se qualificar], o problema é mais uma questão de cultura organizacional, ele entrou e ficou naquele marasmo, ele passou no concurso, "ah tô aqui e ninguém me tira mais", e as pessoas tendem a se acomodar se não são dados desafios, não é!? (Entrevista 10).

Falta de repente um pouco de incentivo, um pouco de esclarecimento para que o servidor possa querer se qualificar (Entrevista 12).

Prefeituras de uma maneira geral investem pouco nisso [qualificação dos funcionários]. [...] Iniciativas esporádicas tem, mas não existe uma consciência de que a qualificação seja necessária para um bom desempenho, de uma maneira geral isso não acontece (Entrevista 06).

Para os entrevistados, a formação superior não é algo que qualifique e habilite os funcionários públicos a exercerem suas atividades de forma mais eficiente para transformar a administração pública. Contrariamente, Levy (2001) explica que a capacitação tem um enorme papel a cumprir no sentido de reposicionar o setor público sim, e ainda ressalta a motivação que a capacitação pode promover. Para essa autora, a capacitação tem um espaço decisivo no serviço público, assim como em outras organizações, pois o Estado é uma das maiores organizações existentes no Brasil, com pluralidade de funções que estão se transformando continuamente, o que demanda um processo de "recapacitação" e requalificação no mesmo ritmo, tendo em vista as grandes transformações que vêm ocorrendo na sociedade do conhecimento (Levy, 2001). 
Por meio de pesquisa in loco, a existência de administração indireta no município foi confirmada em todos os anos pesquisados, ou seja, de 2001 a 2008 houve, de alguma forma, a contratação de algum serviço terceirizado pela administração pública do município. A terceirização de serviços pode estimular a competição, induzir os custos por meio de uma gestão que enfatiza metas, além de proporcionar autonomia gerencial, ou seja, pode fazer com que a administração pública aumente a efetividade, eficiência e responsabilidade na forma como os serviços são oferecidos (Osborne e Gaebler, 1995). Porém, alguns autores lembram que é preciso que os gestores públicos tenham capacidade para a coordenação da contração desses serviços, para que o custo não seja maior que o benefício (Manning et al., 2009).

Para os entrevistados há grandes desvantagens em utilizar a administração indireta, pois ressaltam que muitas vezes o serviço terceirizado não é efetuado da forma como foi contratado.

$\mathrm{Eu}$, sinceramente acho que a prefeitura poderia gerir sozinha todo o trabalho. Acho que teria uma condição melhor, mais empregos, e geralmente, essas firmas terceirizadas são muito caras, paga muito, eu acredito que a própria administração poderia cuidar dessas partes (Entrevista 01).

Acontece o seguinte, a firma ganha a licitação, a prefeitura não fiscaliza e no fim das contas não fica boa a construção (Entrevista 04).

A falta de fiscalização é do próprio sistema, às vezes, né. Do próprio gestor, nem digo do prefeito, mas às vezes um secretário responsável pela pasta ele não desenvolve um trabalho bom. Aí quando o prefeito percebe isso aí, quando o cidadão vem à prefeitura e começa a questionar, aí é que as coisas vão ser apuradas [...] (Entrevista 12).

Conforme Manning e colaboradores (2009:109), a utilização da administração indireta faz com que a organização pública "tire proveito da melhor capacidade operacional dos agentes privados, tendo potencial de melhorar tanto a responsabilidade quanto o desempenho". Porém, para que isso aconteça é preciso que os gestores públicos façam uso de estratégias de fiscalização e acompanhamento eficientes que permitam questionar o que foi contratado. Nesse sentido, Kettl (2005:115) afirma que para o sucesso das terceirizações é indispensável que as pessoas que atuaram no processo de compra desses serviços sejam treinadas e capacitadas para "determinar de antemão o que querem comprar; definir detalhadamente as especificações, para que os fornecedores saibam precisamente o que oferecer; e calibrar a produção para que o comprador possa avaliar a qualidade do que compra".

O indicador instrumentos de gestão (código de obras, lei de parcelamento do solo, lei de zoneamento, plano diretor e cobrança de IPTU) tem por objetivo propiciar um melhor desenvolvimento da gestão municipal, de forma que sejam capazes de colaborar com o alcance dos objetivos e necessidades mais relevantes do município e da sociedade (Rezende e Castor, 2005). A administração do município estudado possui todos os instrumentos citados acima. 
Porém, para os entrevistados, a maior dificuldade para utilização desses instrumentos é com relação à falta de cumprimento das normas desses instrumentos por parte da população, e isso muitas vezes ocorre por falta de fiscalização por parte da prefeitura.

[...] o que acontece com maior frequência é o desrespeito às leis. Então, o que falta são mais fiscais, mais cobrança, uma forma de cobrança para que seja mais certa, mais rápida. Para que sirva de exemplo àqueles que tentem não cumprir também. Então o que falta é um conjunto de ações para fazer com que as leis sejam cumpridas (Entrevista 13).

[...] o povo não respeita a prefeitura, as leis municipais que existem. Hoje você tem lei pra tudo, mas infelizmente o povo também não ajuda e não respeita (Entrevista 14).

De acordo com os relatos dos entrevistados e tendo como base os pressupostos da literatura sobre o uso de instrumentos legais, percebe-se que, de forma geral, os mesmos concordam que tais instrumentos facilitam sim a gestão do município. Entende-se que há por parte dos entrevistados uma relevante consciência da importância desses instrumentos para um bom desenvolvimento do município. Os entrevistados entendem que o planejamento, seguido de normas e metas, é importante para o alcance dos resultados.

[...] você para administrar uma cidade, se você não tiver uma lei, não tiver regulamentos, não tiver normas, você não consegue implantar nenhum tipo de crescimento ordenado, que é o princípio da administração (Entrevista 14).

A utilização de termos como normas, procedimentos e leis não é exclusiva do modelo burocrático, a administração pública gerencial não dispensa o uso de tais termos, mas o faz de forma flexível, procurando mais agilidade aos processos.

O indicador articulação institucionais e participação do cidadão tem como objetivo demonstrar que as articulações entre governo, comunidade e iniciativa privada permitem que as atividades que persistem sob a responsabilidade do Estado sejam reorganizadas por meio da proliferação de formas híbridas de organização, que se traduz em serviços com mais qualidade e agilidade (Kettl, 2005). Para esse autor, essa é, também, uma forma de descentralização da gestão pública que facilita a participação da sociedade, de forma que essa seja mais transparente e participativa. Isso está relacionado ao que Osborne e Gaebler (1995) denominam de "governo catalisador". O sentido do governo catalisador é reformular as relações Estado/ mercado e governo/sociedade. Os processos participativos permitem um movimento de colaboração entre cidadãos e setores privados da sociedade e o setor público, envolvendo troca de conhecimentos e realização de processo decisório, o que permite, sobretudo, o amadurecimento da sociedade diante das questões públicas (Osborne e Gaebler, 1995).

Considerando a existência de consórcio público com outros entes federativos, houve uma grande evolução entre 2002 e 2007, ou seja, a prefeitura aumentou sua articulação de três consórcios com outros entes federativos para sete. Porém, quando analisadas a existência 
de apoio do setor privado ou de comunidades na administração municipal e a existência de convênio ou parceria com o setor privado, visualiza-se que a quantidade de parceria de 2002 a 2007 diminuiu significativamente. Enquanto a prefeitura procurou se articular com outros entes federativos (estados e União), afastou-se de convênios e parcerias com o setor privado e com outras comunidades. Quanto à participação em comitê de bacia hidrográfica verificou-se a participação do município apenas na gestão 2005 a 2008.

Por meio dos depoimentos dos entrevistados, percebe-se certa resistência para a incorporação de uma relação mais participativa entre setores da sociedade e a prefeitura. Acredita-se que os gestores públicos do município dotavam-se de pouca capacidade para fazer com que essas articulações acontecessem. Afirmação essa salientada pelos entrevistados quando questionados sobre as dificuldades da prefeitura para o fortalecimento dessas articulações:

[...] é de fundamental importância que tenha pessoas qualificadas no município, que tenha conhecimento com os diretores, técnicos, saiba como funcionam os projetos, para haver a sintonia entre os gestores, diretores das empresas privadas e os ministérios, para que haja essa sintonia [...]. É isso que precisa, de gente capacitada para que a coisa funcione (Entrevista 09).

A prefeitura tem o consórcio da saúde, e tem o consórcio da Amalg, né. O consórcio da saúde são vários municípios, que existe uma parceria aí [...]. E, com relação à Amalg, é um consórcio, é uma associação que investe na qualidade dos servidores e possui também no seu quadro equipamentos que dão apoio a prefeituras em relação a obras, estradas rurais (Entrevista 01).

Com relação à articulação entre o setor público do município e a comunidade tem-se por meio do entendimento dos entrevistados que a participação cidadã no município é ainda muito incipiente e de pouco interesse.

Ah, isso é cultura mesmo. É cultura brasileira [...] muito pouca gente se interessa em participar. "Eu ir lá, pra ajudar os outros, pra quê? Isso não vai me beneficiar em nada." A grande maioria pensa em si própria, poucos querem ajudar, fazer, ver o benefício da comunidade, são poucos, muito poucos (Entrevista 01).

Quando perguntados sobre essas articulações, os entrevistados fazem questão de mencionar os modelos de articulações que foram utilizados pela prefeitura do município e, mais ainda, quais os benefícios advindos dessas articulações. Mesmo as perguntas sendo referidas às gestões de 2001 a 2008, alguns entrevistados se remetem à gestão atual, reafirmando com mais propriedade o uso dessas articulações e sua importância para a gestão do município.

Os entrevistados reforçam que essas articulações são importantes devido à impossibilidade de a prefeitura atender as demandas do município; assim, consideram as parcerias como uma forma de atender a população e de executar as demandas que muitas vezes surgem inesperadamente. 
Conforme Cunha (2007:1), a não participação do cidadão é uma questão cultural herdada "de uma tradição autoritária, que rejeita a participação política das massas e discrimina cidadãos hierarquicamente". Para Baquero e Prá (1995), a dificuldade de fazer com que o cidadão tome consciência da importância de sua participação se dá devido aos resquícios de uma cultura composta por valores como o autoritarismo e práticas como o clientelismo e o patrimonialismo.

Seguindo esse entendimento, Medauar (2003) afirma que, para que seja possível aproximar os cidadãos da administração pública, é necessário que sejam fixados não modelos processuais, mas princípios informadores da relação entre os mesmos. Ressalta-se aí a importância dos gestores públicos em promover meios para que os cidadãos se conscientizem da importância de sua participação.

Pode-se dizer, de forma geral, que os entrevistados concordam e entendem que os conselhos gestores são peças-chave para uma gestão pública baseada em relações democráticas e dialógicas entre sociedade e Estado. Por meio dos relatos dos entrevistados entende-se que os mesmos veem a troca de informações entre população e poder local como uma das principais vantagens dos conselhos gestores para a gestão administrativa do município. Para os entrevistados essa troca de informação facilita o entendimento por parte da gestão quanto às demandas da sociedade, fazendo assim com que sejam priorizadas as necessidades e que também se faça valer a opinião da população.

Podem contribuir demais, os conselhos gestores são instrumentos fantásticos para qualquer administração. Nós temos que multiplicar esses conselhos. É uma forma de descentralizar a administração, você entendeu? Eu vejo com muito bons olhos essa questão, eu acho que é uma questão que tem que estar sempre em crescimento os conselhos gestores. Eles têm que ser ampliados e haver uma interação maior com a administração pública, uma participação. Porque aí o gestor público, o prefeito municipal ou a prefeita pode estar tomando conhecimento mais de perto dos problemas e das soluções sugeridas porque nós não podemos achar [que] quem está administrando o município hoje é somente o prefeito, que ele sabe tudo e tenha solução para tudo e os conselhos gestores, nós estamos nas bases, eu acho que é muito importante o conselho gestor (Entrevista 13).

O conselho é composto por pessoas da sociedade, dos bairros, e sabem as necessidades que o pessoal do bairro passa. Aí o pessoal do conselho vai mostrar para o gestor público o que a cidade tá precisando, [...]. Então cada bairro precisa de uma coisa, então você vai fazer um planejamento, e o conselho é que vai decidir. Acho isso fundamental, é onde fecha a administração toda (Entrevista 14).

Um dos primeiros problemas apontados pelos entrevistados sobre a consolidação da parceria entre prefeitura e conselhos gestores é a não participação da população. Para eles a efetividade da ação ou atuação da comunidade nessa relação é muito pouco representativa. 
Eles afirmam ainda que isso ocorre devido à cultura da sociedade, que não estimula o envolvimento dos cidadãos/indivíduos nos assuntos da comunidade.

Portanto, entende-se que o município possui baixa capacidade de se articular com os cidadãos e com os setores privados da comunidade, o que pode inibir iniciativas ou mesmo alternativas para o atendimento das demandas do município, o que, por sua vez, poderá comprometer o desenvolvimento municipal.

O indicador responsabilidade fiscal e aplicação dos recursos permite ter uma visão quanto ao equilíbrio fiscal do município e a eficiência na aplicação de seus recursos, fatores esses primordiais em um modelo de administração pública gerencial (Freitas Jr., 2009). Assim, as questões efetuadas com relação a esse indicador tiveram como objetivo analisar, segundo a visão dos entrevistados, quais são as dificuldades e os possíveis entraves para o cumprimento do percentual estabelecido em lei (aplicação de recursos em saúde, educação e despesas com pessoal; cumprimento da Lei de Responsabilidade Fiscal; cumprimento de limites legais para o endividamento do município; cumprimento dos limites da participação da dívida na receita corrente líquida e realização de esforço orçamentário em educação/saúde).

Considerando que a Lei de Responsabilidade Fiscal determina que todos os municípios e estados gastem, obrigatoriamente, o percentual mínimo de 15\% em educação, em relação às receitas de impostos e transferências, verificou-se que, somente no ano de 2001, esse percentual não foi atingido no município estudado. Por outro lado, com respeito ao percentual mínimo de $25 \%$ em saúde, em todos os anos pesquisados o município estudado gastou mais do que esse mínimo previsto em lei. Os dados demonstram que o esforço orçamentário em saúde, no período analisado, ultrapassou o mínimo exigido por lei, o que expressa o empreendimento das duas gestões analisadas em investir na saúde. Dessa forma, a gestão pública do município mais que cumpriu uma meta determinada em lei e demonstrou empenho e rigor na aplicação de recursos na área da saúde. Nesse caso, a gestão pública desse município se aproxima muito do gerencialismo.

Com relação ao percentual máximo de $60 \%$ de gastos com pessoal em proporção à receita corrente líquida (RCLL), considera-se que, quanto menor for o índice de gasto do município, mais ele é considerado eficiente. Por meio dos dados analisados, o município estudado nunca ultrapassou o limite determinado. Porém, a gestão de 2001 a 2004 teve um desempenho melhor, ou seja, apresentou um percentual abaixo de $40 \%$ nos quatro anos, enquanto na gestão posterior os gastos com pessoal ficou acima de $40 \%$ no período. Tal fato está relacionado com o indicador de recursos humanos, o qual mostra ao longo das duas gestões um crescimento significativo do número de funcionários.

Quando questionada sobre as dificuldades e possíveis entraves para o cumprimento dessas metas/leis, a maioria dos entrevistados concorda que não há grandes empecilhos e resume essas dificuldades e possíveis entraves exclusivamente à falta de capacitação de quem está à frente da gestão.

Não tem dificuldade (para o cumprimento do percentual em saúde, educação e/ou pessoal) nenhuma. Basta administrar à altura. Você coloca um secretário de educação que tenha conheci- 
mento na área de educação, coloca um auxiliar para ele que tenha conhecimento nas áreas afins da educação, [...] você consegue administrar tudo tranquilamente, desde que você tenha uma equipe à altura (Entrevista 03).

[...] Os administradores precisam ser eficientes [...]. Então acho que hoje, as pessoas que estão à frente do poder público, elas têm que montar uma equipe para acompanhar e gerenciar de forma efetiva essa Lei [Lei de Responsabilidade Fiscal] [...] (Entrevista 09).

Para os entrevistados, a "incapacidade" dos gestores públicos novamente aparece como um dos grandes entraves do gerenciamento das demandas da administração do município. Para eles era preciso, para o cumprimento dessas metas/leis, a elaboração de um eficiente planejamento estratégico, que é, de fato, uma das funções clássicas da administração gerencial. Assim, entende-se que para alcançar o cumprimento das metas e atender às leis que regem a administração pública municipal é necessária a profissionalização dos gestores públicos.

\section{Considerações finais}

Grande tem sido o esforço do Estado brasileiro para a efetivação do modelo de administração gerencial. Porém, constata-se que a adoção do modelo ainda não é efetiva nos três níveis de governo.

Foram identificados vários entraves que dificultam ou impedem a adoção do gerencialismo na administração pública municipal, quais sejam: falta de capacidade de gerenciamento e controle dos gestores públicos com base nos pressupostos do modelo; falta de incentivo por parte dos dirigentes para a capacitação e qualificação dos funcionários; ausência de políticas e mecanismos que permitam a valorização e a motivação dos funcionários; falta de iniciativa e criatividade por parte dos gestores do município em promover as ações direcionadas para mudanças organizacionais e sociais; não cumprimento de forma equilibrada das despesas de acordo com as receitas do município; inexistência de postura empreendedora; baixa capacidade dos dirigentes municipais em se articular com os cidadãos e com os setores privados da comunidade; presença de características autoritárias e patrimonialistas na gestão pública. Portanto, os gestores públicos não conseguem se articular e pôr em prática os princípios gerenciais.

A maioria dos entrevistados expressou a falta de profissionalismo na gestão como principal entrave, mas não explicou por que não se esforçou para aumentar ou melhorar o nível de capacitação da equipe ao longo de sua gestão. A falta de pessoas capazes de introduzir um planejamento estratégico, de estabelecer objetivos de longo prazo e metas a serem cumpridas no curto prazo e de conduzir todo o processo gerencial são outros entraves apresentados pelos entrevistados.

Para que o modelo de administração pública gerencial, assim como qualquer outra iniciativa de reforma administrativa, se efetive é primordial que haja preparação técnica e política dos gestores públicos. Portanto, como forma de superar os entraves identificados para 
a adoção efetiva do modelo gerencial, acredita-se que seja necessário que os governantes públicos se qualifiquem em curso superior e pós-graduação em administração pública, bem como todo o funcionalismo público municipal. Para isso, a existência de um plano de carreira municipal é fundamental.

Acredita-se, também, que reformas como a do modelo gerencial, para serem efetivas na administração pública municipal, precisam levar em conta a participação social por meio dos conselhos gestores de políticas públicas e por meio de outros canais de participação democrática.

Deve-se considerar que os resultados aqui obtidos dizem respeito somente ao município estudado. A aplicação desse mesmo estudo em outros municípios pode apresentar resultados diferenciados. Nesse sentido, novas pesquisas nessa área em vários municípios ou categorias de municípios poderão elucidar melhor os problemas de ordem administrativa municipal, bem como criar possibilidades objetivas de teorizar a prática gerencial no Brasil.

\section{Referências}

ABRUCIO, Fernando L. Os avanços e os dilemas do modelo pós-burocrático: a reforma da administração pública à luz da experiência internacional recente. In: BRESSER-PEREIRA, Luiz C.; SPINK, Peter K. (Org.). Reforma do Estado e administração pública gerencial. 7. ed. Rio de Janeiro: Fundação Getulio Vargas, 2005. p. 173-200.

BAQUERO, Marcelo; PRÁ, Jussara R. Matriz histórico-estrutural da cultura política no Rio Grande do Sul e padrões de participação política. Cadernos de Ciência Política, Série Pré-edições, Porto Alegre, n. 3, 1995.

BRASIL. Presidência da República. Plano diretor da reforma do aparelho do estado. Brasília, 1995. $68 \mathrm{p}$.

BRESSER-PEREIRA, Luiz C. Gestão do setor público: estratégia e estrutura para um novo Estado. In: BRESSER-PEREIRA, Luiz C.; SPINK, Peter K. (Org.). Reforma do Estado e administração pública gerencial. 7. ed. Rio de Janeiro: Fundação Getulio Vargas, 2005. p. 21-28.

CUNHA, Patrícia. R. C. da. A participação cidadã dos jovens cearenses em questão. In: SEMINÁRIO NACIONAL MOVIMENTOS SOCIAIS, PARTICIPAÇÃO E DEMOCRACIA, 2., 2007, Florianópolis. Anais... Florianópolis: UFSC, 2007. 1 CD-ROM.

CUNHA JUNIOR, Luiz A. P. da. O governo matricial em Minas Gerais: implantando o Choque de Gestão. In: CONGRESSO INTERNACIONAL DEL CLAD SOBRE LA REFORMA DEL ESTADO Y DE LA ADMINISTRACIÓN PÚBLICA, IX, 2004, Madrid. Disponivel em: <nfr://www.clad.org.ve/ fulltext/0049619.pdf>. Acesso em: 20 fev. 2010.

FADUL, Élvia M. C.; SILVA, Mônica A. M. Limites e possibilidades disciplinares da administração pública e dos estudos organizacionais. In: ENANPAD 2008 - ENCONTRO DA ASSOCIAÇÃO NACIONAL DE PÓS-GRADUAÇÃO EM ADMINISTRAÇÃO, 2008, Rio de Janeiro. Anais... Rio de Janeiro: Anpad, 2008. CD-ROM. 
FREITAS JR., Dionysio B. Avaliação da administração pública gerencial em municípios por meio de indicadores. 2009. 139 p. Dissertação (mestrado em administração) - Universidade Federal de Lavras, Lavras, 2009.

GIDDENS, Antony. A terceira via. Rio de Janeiro: Record, 1999. 176 p.

HOOD, Christopher. The new public management. In: the 1980s: Variations on a Theme. Accounting Organizations and Society, v. 20, n. 2/3, p. 93-109, 1995.

HYNEMAN, Charles S. Administrative reorganization: an adventure into science and technology. Journal of Politics, v. 1, p. 63-75, 1939.

IBGE. Instituto Brasileiro de Geografia e Estatística. Perfil dos municípios. Disponível em: <www. ibge.gov.br/home/estatistica/economia/perfilmunic/default.shtm>. Acesso em: 5 maio 2010.

KAUFMAN, Herbert. Emerging conflicts in the doctrines of public administration. The American Political Science Review, v. 50, n. 4, p. 1057-1073, 1956.

KETTL, Donald F. A revolução global: reforma da administração do setor público. In: BRESSERPEREIRA, Luiz C.; SPINK, Peter K. (Org.). Reforma do Estado e administração pública gerencial. 6. ed. Rio de Janeiro: Fundação Getulio Vargas, 2005. p. 75-122.

LEVY, Evelyn. Teleconferência para apresentar o Sistema de Acompanhamento de Capacitação — Sifac. Brasília: Ministério do Planejamento, Orçamento e Gestão, 17/12/2001. (Evelyn Levy — Secretaria de Gestão do MOG — Governo Federal).

LIGHT, Paul C. Tides of reform: making government work 1945-1995. New Haven: Yale University Press, 1997.

MANNING, Nick et al. Reformas de gestão pública: o que a América Latina tem a aprender com a OCDE? In: MEDEIROS, Paulo C.; LEVY, Evelin (Org.). Novos caminhos da gestão pública: olhares e dilemas. Rio de Janeiro: Qualitymark; Brasília: Consad, 2009. p. 97-148.

MARCH, James G.; OLSON, Johan P. Organizing political life: what administrative reorganization tells us about government. American Political Science Review, v. 77, n. 2, p. 281-296, jun. 1983.

MEDAUAR, Odete. O direito administrativo em evolução. São Paulo: Revista dos Tribunais, 2003. 298 p.

MISOCZKY, Maria Ceci A. Uma defesa da reflexão teórica crítica na pesquisa e prática da administração pública. In: ENCONTRO NACIONAL DE ADMINISTRAÇÃO PÚBLICA E GOVERNANÇA, 1., 2004, Rio de Janeiro. Anais... Rio de Janeiro: Anpad, 2004. 1 CD-ROM.

OSBORNE, David; GAEBLER, Ted. Reinventando o governo: como o espírito empreendedor está transformando o setor público. 7. ed. Brasília: MH Comunicação, 1995. 436 p.

PAES DE PAULA, Ana P. Por uma nova gestão pública: limites e potencialidades da experiência contemporânea. Rio de Janeiro: FGV, 2005. 204 p.

POLLIT, Christopher. Is the emperor in his underwear? An analysis of the impacts of public management reform. Public Management, v. 2, n. 2, p. 181-199, 2000. 
REZENDE, Denis A.; CASTOR, Belmiro V. J. Planejamento estratégico municipal: empreendedorismo participativo nas cidades, prefeituras e organizações públicas. Rio de Janeiro: Brasport, 2005. 156 p.

REZENDE, Flávio da C. Por que reformas administrativas falham? Revista Brasileira de Ciências Sociais, v. 17, n. 50, p. 123-142, out. 2002.

TORRES, Marcelo D. de F. Estado, democracia e administração pública no Brasil. Rio de Janeiro: FVG, 2004. 224 p.

VILHENA, Renata et al. O choque de gestão em Minas Gerais: políticas da gestão pública para o desenvolvimento. Belo Horizonte: Editora UFMG, 2006. 363 p.

Priscila Gomes de Araújo é mestre em administração pela Universidade Federal de Lavras (Ufla). E-mail: priscila2210@yahoo.com.br.

José Roberto Pereira é professor associado da Ufla. E-mail: jrobpereira25@yahoo.com.br. 
